\title{
Território, ambiente e modos de vida: conflitos entre o agronegócio e a Comunidade Quilombola de Morro de São João, Tocantins
}

\author{
Territory, environment and way of life: conflicts between the \\ agribusiness and the Quilombola Community Morro de São João, \\ Tocantins
}

\author{
Lucas Barbosa e Souza ${ }^{1}$ \\ Eguimar Felício Chaveiro ${ }^{2}$
}

\begin{abstract}
Resumo
Este artigo busca discutir as implicações do avanço do agronegócio sobre uma comunidade quilombola no Estado do Tocantins (Brasil), considerando o conflito a partir das dimensões territorial, ambiental e do modo de vida dos moradores. Para essa abordagem, a principal estratégia metodológica foi a pesquisa de campo, por meio de entrevistas qualitativas com membros da comunidade. Os resultados demonstram que a perda do território tradicional para o agronegócio, ou seja, a questão fundiária, é determinante para a ocorrência de problemas ambientais (desmatamento, escassez hídrica, uso de agrotóxicos, perturbação à fauna e à flora), o que altera profundamente os hábitos e o cotidiano dos quilombolas.

Palavras-chave: Território; Ambiente; Comunidade quilombola; Avanço do agronegócio; Modo de vida.
\end{abstract}

\begin{abstract}
This paper seeks to discuss the implications of the agribusiness expansion on a quilombola community in the Tocantins State (Brazil), considering the conflict at the perspective of the territorial and environmental dimensions and the way of life of the dwellers. For this approach, the main methodological strategy was the field research, by qualitative interviews with the community members. The results show that the loss of the traditional territory to the agrobusiness, that is, the land question, is determinant to the environmental problems occurrence (deforestation, water shortage, use of agrochemicals, disturbance to fauna and flora), which change deeply the habits and the everyday life of the quilombolas.

Keywords: Territory; Environment; Quilombola community; Agribusiness advance; Way of life.
\end{abstract}

\footnotetext{
${ }^{1}$ Universidade Federal do Tocantins (UFT), Porto Nacional, Tocantins, Brasil. lbsgeo@uft.edu.br

2 Universidade Federal de Goiás, (UFG), Goiânia, Goiás, Brasil. eguimar@hotmail.com

Artigo recebido em: 18/05/2018. Aceito para publicação em: 10/12/2018.
} 


\section{Introdução}

À medida que o agronegócio se expande e se territorializa pelo país leva consigo uma série de implicações ambientais, em especial para aqueles grupos que construíram, até então, uma relação de profunda interdependência com a natureza em seus modos de vida, como é o caso das comunidades tradicionais. A problemática que emerge desse fato explicita, por conseguinte, a articulação entre o território e o ambiente nos espaços de fronteira agrícola.

De acordo com Suertegaray (2017), o conceito de ambiente pressupõe a transfiguração da natureza pelas práticas sociais, especialmente pelas práticas socioprodutivas, que alteram tanto o metabolismo próprio da natureza, quanto o metabolismo da relação entre os seres humanos e a natureza. $\mathrm{O}$ ambiente torna-se revelador da tensão entre a organização social, a apropriação do espaço, o uso/exploração dos seus recursos e suas várias consequências. Assim, "as questões ambientais são, antes de tudo, questões territoriais. Desse modo, os conflitos ambientais-territoriais são sobretudo conflitos políticos" (SUERTEGARAY, 2017, p.155). Como está enunciado, a concepção de ambiente em curso, ao se posicionar no interior da questão territorial, instrui a pensar o jogo dialético, ou as disputas sociais sobre os componentes naturais. Com efeito, os problemas ambientais são, assim, problemas de ordem da estruturação do poder - e de seus desígnios políticos.

Tais conflitos pressupõem, na maioria dos casos, situações de injustiça ambiental, que segundo Acselrad et al (2009), ocorrem quando há distribuição/apropriação desigual dos custos e benefícios de um modelo de desenvolvimento (promovido por agentes públicos, privados ou, não raramente, por ambos), de modo mais amplo, ou de um determinado empreendimento, em casos mais específicos. Em relação ao agronegócio e ao sistema produtivo habitualmente empregado, as injustiças podem referir-se à concentração de terra e ao uso de bens comuns como a água e o solo, bem como também ao efeito dispersivo de insumos e resíduos. As diferentes 
reações a essas injustiças, ainda que de forma desproporcional (dadas as diferenças de poder econômico e político entre os grupos envolvidos), é o que poderá caracterizar uma situação de conflito, ressaltando o aspecto dialético do tema. Pode-se dizer que a aliança entre Estado, latifundiários e demais agentes vinculados ao agronegócio, ao dispor da terra pela via da estratégia economicista - e gerar problemas ambientais face ao modo pelo qual a terra é usada - desdobra-se na injustiça ambiental consoante a injustiça social.

Para Zhouri e Laschefski (2010, p.17), “[...] os conflitos ambientais surgem das distintas práticas de apropriação técnica, social e cultural do mundo material [...], envolvem as relações entre poder e meio ambiente no terreno", o que reforça seu viés territorial. Ainda segundo os autores, os conflitos estão divididos em distributivos (relacionados às desigualdades sociais de acesso e uso dos bens comuns), espaciais (relacionados à disseminação ou extrapolação espacial dos efeitos ambientais indesejados de uma ação), e propriamente territoriais (em que há sobreposição de interesses, entre grupos sociais distintos, sobre a mesma porção do espaço).

Nos casos que envolvem conflitos territoriais e ambientais entre o agronegócio e comunidades tradicionais, tem havido, com frequência, a limitação do acesso dos segundos à própria natureza, o que influencia em sua sobrevivência tanto material quanto simbólica. Casos desse tipo são demonstrados por Almeida (2010), Chaveiro (2010), Barbosa e Camenietzki (2011), por meio de situações vivenciadas por povos indígenas e quilombolas no Brasil, somente para citar alguns exemplos.

Porém, a tônica dos conflitos nem sempre comparece nas leituras das questões ambientais contemporâneas, quando por inúmeras vezes se perde a oportunidade para realçar o sentido das transfigurações da natureza para a própria sociedade e as disputas envolvidas. Como ilustração, na seara das relações entre clima e agricultura, percebe-se em publicações das últimas décadas uma abordagem frequentemente reducionista, que privilegia a questão adaptativa da produção de alimentos às novas condições climáticas 
em diferentes lugares do mundo (MEINKE et al, 2009; McCARL, 2010; OSÓRIO e AZEVEDO, 2014; JAKKU et al, 2016, entre outros). Por seu turno, presta-se pouca atenção às mudanças ambientais provocadas pelo desmatamento e pelas monoculturas promovidos pelo agronegócio, assim como às relações interescalares entre causas e consequências dessas mudanças, quando trata-se de grupos humanos afetados, em escala local. Nesses casos, é justamente a produção de commodities agrícolas o que tem contribuído para a redução da agrobiodiversidade e da produção de alimentos por comunidades tradicionais, o que institui conflitos territoriais e ambientais.

Diegues (2000) defende os sistemas produtivos dessas comunidades, em detrimento do modelo produtivo da agricultura comercial de larga escala, no sentido em que contribuem para a própria conservação da biodiversidade. Ressalta que as técnicas de manejo ancestrais empregadas por elas podem auxiliar na regeneração florestal e na manutenção de espécies animais em seus territórios, entre outros benefícios. Com base nesse raciocínio o autor propõe o conceito de sociobiodiversidade, capaz de retratar a variedade, tanto biológica quanto sociocultural, que forma um continuum no ambiente, favorecendo a conservação da natureza concomitantemente à presença humana (DIEGUES, 2005).

Mazzetto-Silva (2009) afirma que até a década de 1980, mais da metade do Cerrado brasileiro estava composto por áreas de paisagens naturais manejadas por grupos tradicionais (pastagem natural, extrativismo etc.), que vêm sendo "ou substituída[s] ou encurralada[s] pelas monoculturas modernas" (MAZZETTO-SILVA, 2009, p.98), o que reflete diretamente nos modos de vida e sobrevivência dessas comunidades. Hoefle (2017) considera que o grau de capitalização e as características culturais de diferentes grupos sociais estão diretamente relacionados aos aspectos da ética ambiental no uso/exploração da natureza em áreas de fronteira agrícola recente na Amazônia, apontando um processo de proletarização de pequenos 
proprietários, que passam à condição de empregados nas propriedades maiores. Nota-se, então, como a expansão do agronegócio tem alterado em diferentes dimensões a vida de determinados grupos no campo.

O conjunto de ações, logísticas, forças produtivas e estratégias de mercado de terras voltadas à produção de commodities agrícolas reflete a organização geopolítica do domínio mundial do setor produtivo do agronegócio. Atualmente, encontra-se no território tocantinense uma das fronteiras de expansão de tal setor. Valendo-se de critérios da primeira fase da denominada abertura de fronteira no mundo do Cerrado, a expansão do agronegócio no Tocantins faz uso do preço barato das terras; do incentivo das esferas federal e estadual; e do discurso ideológico de que a expansão do setor será a alavanca do desenvolvimento econômico e social das áreas em que se instala (LIMA, 2015).

Em termos de mudanças ambientais, pode-se ressaltar, em um primeiro momento, o papel do desmatamento. De acordo com Richards (2015), a presença da soja causa mudanças diretas e indiretas no uso do solo, ao afetar o mercado de terras, ocupar áreas de antigas pastagens e forçar a abertura de novas áreas para a pecuária, via desmatamento, visto como um investimento produtivo quando há uma conjuntura favorável. Na esteira do desmatamento, seguem as demais alterações ambientais nas áreas de cultivo e em seu entorno, como aquelas relacionadas ao balanço de energia (aumento do calor), aos fluxos hídricos e à contaminação por agrotóxicos, além de implicações sobre a fauna (por exemplo, afugentamento e mudanças de hábitos alimentares e reprodutivos) e a flora (tais como o gradual desaparecimento de determinadas espécies nativas).

Na esteira da capital (Palmas) e do polo regional de Porto Nacional, a partir das possibilidades de gestão da terra, da lógica de transporte e de comunicação e da planura do relevo, vem ocorrendo a expansão do agronegócio em direção ao município de Santa Rosa do Tocantins, localizado no centro-sul 
do estado (Mapa 1) . Assim, esse município tem experimentado um significativo avanço das lavouras de soja desde o início da década de 2000.

Mapa 1 - Localização de Santa Rosa do Tocantins (TO)

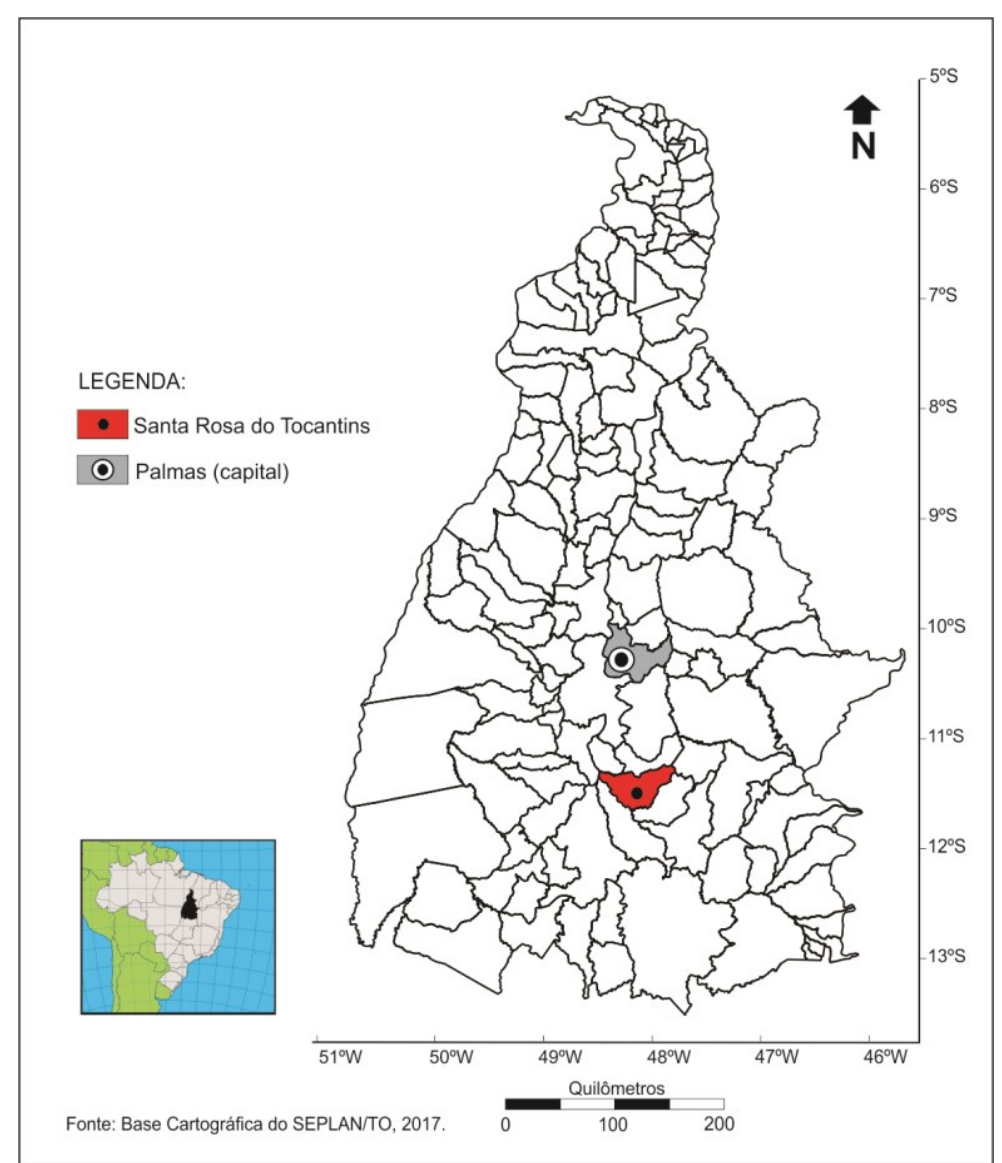

Org: dos autores, 2018.

Os dados disponibilizados pelo portal eletrônico do Laboratório de Processamento de Imagens e Geoprocessamento (LAPIG), do Instituto de Estudos Socioambientais (IESA) da Universidade Federal de Goiás (UFG), por meio da ferramenta Inteligência Territorial (UFG, 2017), demonstram que o município de Santa Rosa do Tocantins passou por um desmatamento acumulado de 7,64\% de sua área, entre 2008 e 2015, sendo este o maior valor relativo entre os municípios tocantinenses no período. Segundo a mesma fonte, no ano de 2014, o município teve cerca de $15 \%$ de sua área recobertos 
por lavouras de soja, destacando-se entre as principais áreas plantadas no Tocantins.

O município de Santa Rosa do Tocantins abriga a Comunidade Quilombola Morro de São João, em sua porção oeste, atualmente com 113 habitantes agrupados em um pequeno núcleo de moradias (povoado), segundo dados obtidos em campo, entre os meses de dezembro/2017 e janeiro/2018. Trata-se de um quilombo contemporâneo, nos dizeres de Fiabani (2008), por constituir uma comunidade negra rural cuja formação remete a terras doadas por testamento a descendentes da relação entre um padre e uma escrava, no século XIX. A área original, de 1800 alqueires, passou por divisão ao longo das gerações, sendo que a maior parcela transferiu-se para as mãos de fazendeiros externos à comunidade, possibilitando a instalação de propriedades voltadas à pecuária, em um primeiro momento, e, mais recentemente, ao cultivo da soja (CLETO, 2015).

A comunidade quilombola foi formalmente reconhecida pela Fundação Cultural Palmares em 2006, mesmo ano de instauração do processo de regularização fundiária pelo Instituto Nacional de Colonização e Reforma Agrária (INCRA), segundo informações que constam nos sítios eletrônicos dos respectivos órgãos. Carvalho (2011) aponta uma série de dificuldades do INCRA no Tocantins, referentes a recursos materiais e humanos, para avaliar os pedidos de regularização fundiária de comunidades quilombolas no estado, apesar da existência de 44 (quarenta e quatro) territórios já reconhecidos até o ano de 2017. Para Monego et al (2010), a insegurança alimentar que prevalece em comunidades quilombolas no Tocantins encontra-se intimamente relacionada às problemáticas fundiária e ambiental nos territórios. O panorama da Comunidade Quilombola de Morro de São João revela ambas as problemáticas, relacionadas à redução sistemática de seu território ao longo dos anos e às implicações ambientais da prática produtiva do agronegócio da soja, condição semelhante a outras áreas no estado (SOUZA, 2016a). 
Partindo desse contexto, este artigo traz como questão central a seguinte indagação: quais são as tensões provocadas pelo avanço da fronteira agrícola sobre a Comunidade Quilombola Morro de São João, em especial quanto aos aspectos territoriais, ambientais e aos modos de vida?

\section{Construção e execução da pesquisa}

Em termos metodológicos, a pesquisa foi desenvolvida por meio de diferentes estratégias e procedimentos. A principal via de acesso às informações foi o trabalho de campo sistemático, quando foram realizadas entrevistas qualitativas (semiestruturadas) com membros da Comunidade Quilombola de Morro de São João, após aprovação pelo Comitê de Ética em Pesquisa da Universidade Federal de Goiás (UFG), via Plataforma Brasil. A investigação, envolvendo suas diferentes etapas, foi desenvolvida no período de abril/2017 a março/2018 e os trabalhos de campo para a realização das entrevistas foram executados no dia 15 de dezembro de 2017 e nos dias 6, 14 e 20 de janeiro de 2018 .

Um tópico guia foi construído para orientar as entrevistas, levando em consideração os aspectos territoriais, ambientais e dos modos de vida na comunidade, tomando-se como inspiração os trabalhos de Guyot et al (2006) e Barros (2012), que envolveram temas análogos com comunidades tradicionais, por meio de pesquisa qualitativa. A abordagem comparativa entre os períodos anterior e posterior à presença do agronegócio no território quilombola, embora fosse desde o princípio o foco da pesquisa, emergiu naturalmente no conteúdo das entrevistas pelos próprios sujeitos, o que ratificou a importância do tema para a comunidade.

A compreensão do sentido da entrevista qualitativa, de seus limites e potenciais, bem como a preparação para a sua execução, foram ancoradas nas recomendações de Poupart (2008) e Gaskell (2013). A construção do corpus empírico foi realizada gradativamente, por meio da indicação dos próprios 
sujeitos, buscando-se atingir a maior variedade possível de perfis/extratos, porém considerando-se como critérios de inclusão as vivências e os saberes acumulados necessários à abordagem dos temas pautados. Com base no princípio de saturação empírica, quando percebe-se a consistência das informações centrais e a relativa redundância de eventuais novas entrevistas, atingiu-se um número de 12 sujeitos (PIRES, 2008; BAUER; AARTS, 2013).

As entrevistas tiveram duração média de 41 minutos, tendo sido realizadas na moradia dos entrevistados, gravadas em áudio e depois transcritas, seguindo adicionalmente as recomendações de Longhurst (2010). O texto interpretativo, por sua vez, foi construído a partir das questões centrais que emergiram das entrevistas, conforme sugere Cope (2010).

Os trabalhos de campo foram também oportunidades para diferentes observações e registro de notas, conjunto que inevitavelmente auxiliou na abordagem ora apresentada. Por fim, com o intuito de obter a representação espacial do território quilombola e das alterações sofridas quanto à cobertura e ao uso do solo no período recente, foram construídos dois mapas, referentes aos anos 2000 e 2017, a partir de imagens dos sensores Landsat 7 e 8 (resolução espacial de 30 m.), respectivamente, por meio de classificação supervisionada no software ArqGIS 10.2 e edição no software QGIS 2.14.10. Esses mapas fornecem um panorama inicial, a partir do qual prossegue o restante da discussão.

\section{Efeitos do agronegócio na Comunidade Quilombola Morro de São João}

O território reivindicado pela comunidade em seu processo de regularização fundiária encontra-se delimitado pelos rios Tocantins, Manuel Alves e Formiga, além do córrego São Felipe, conforme consta nos mapas 2 e 3. Os mapas demonstram as principais classes de cobertura/uso do solo na área nos anos de 2000 (2) e de 2017 (3), tendo ao centro o povoado de Morro de São João, onde concentram-se os moradores. 
Mapa 2 - Uso/cobertura do solo no território quilombola e arredores (2000)

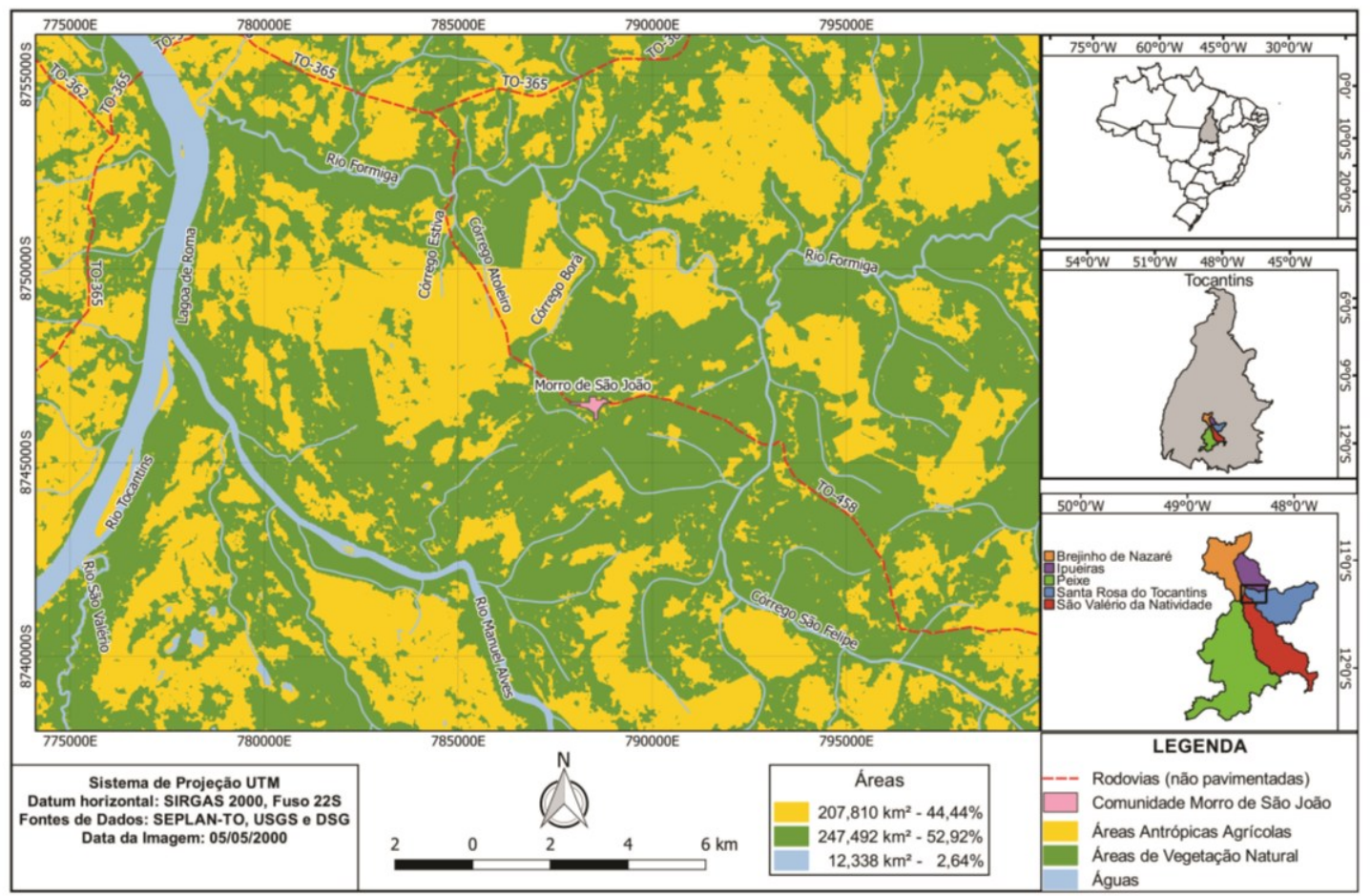

Org: dos autores, 2018.

Mapa 3 - Uso/cobertura do solo no território quilombola e arredores (2017)

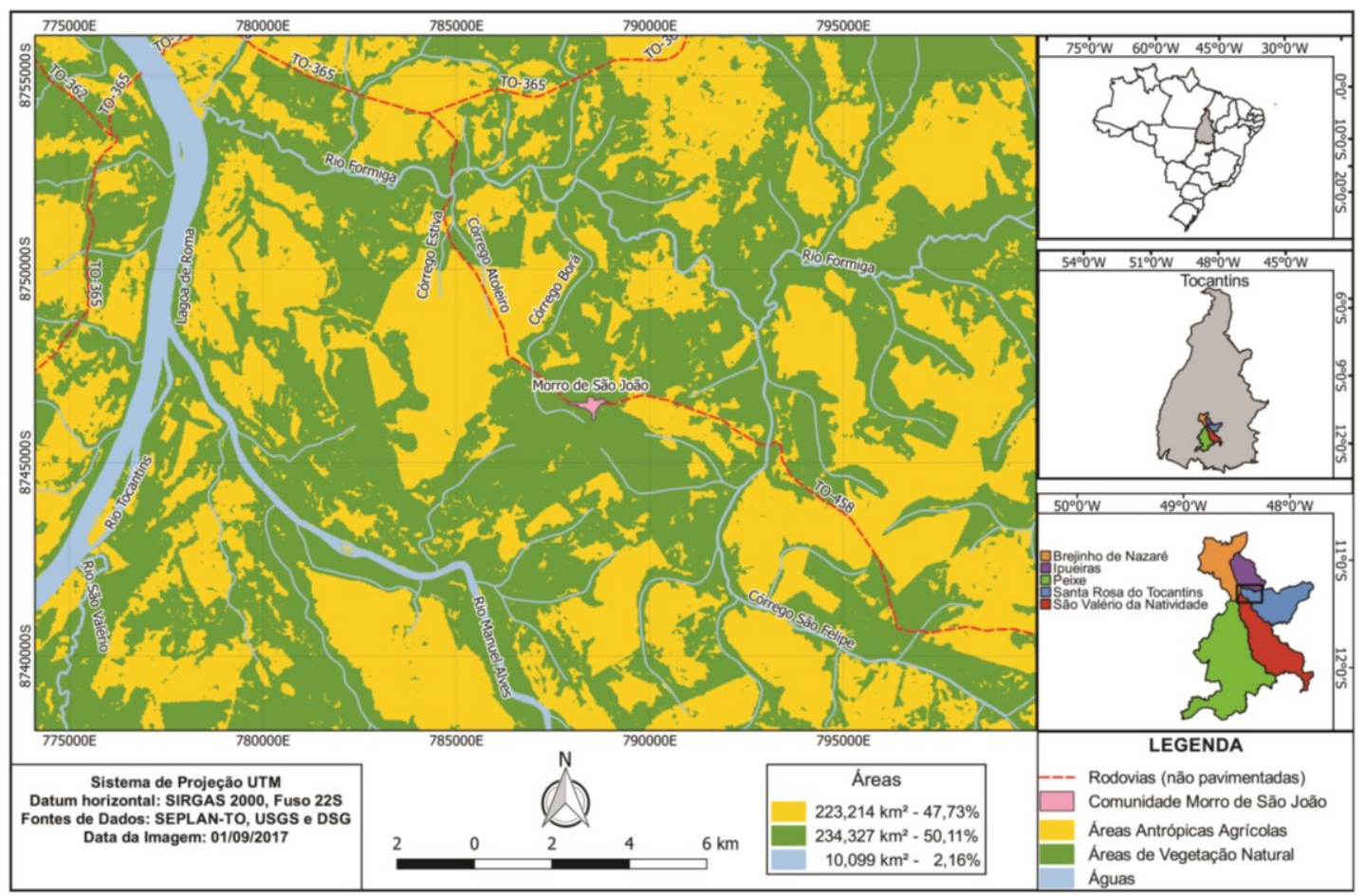

Org: dos autores, 2018. 
A observação dos mapas permite visualizar as mudanças em curso no que diz respeito à supressão da vegetação natural de Cerrado para o aproveitamento agrícola na área, em uma expansão proveniente de sudeste, a partir das áreas de sojicultura já consolidadas no município de Santa Rosa do Tocantins. Percebe-se a posição do território quilombola entre os cursos d'água mencionados, no limite oeste do município, o que faz com que a comunidade seja progressivamente encurralada pela expansão das lavouras, especialmente nos últimos anos (após 2012, segundo informações obtidas durante as pesquisas de campo).

Conforme já mencionado, o corpus empírico dos entrevistados foi composto por 12 sujeitos, sendo nove homens e três mulheres, com média de idade de 59 anos (distribuição entre 36 e 92 anos de idade). A maioria (sete sujeitos) possui nível fundamental incompleto, dois cursam nível superior, um é analfabeto, um possui nível fundamental completo e um possui nível médio completo. Entre os sujeitos, somente dois não possuem grau de parentesco no âmbito da comunidade, tendo sido agregados entre os moradores há 23 anos. O tempo médio de moradia na comunidade é de 47 anos, o que indica profunda relação e conhecimento sobre o território e suas modificações. Metade dos sujeitos se apresentam como lavradores, porém existem outras funções tais como servidor público, estudante e comerciante. Três sujeitos já obtiveram suas aposentadorias. Apenas quatro ainda são detentores de glebas de terra no local. A média de residentes por moradia entre os sujeitos é de 3,3 pessoas, o que reflete a saída de moradores jovens da comunidade, principalmente para cidades da região, em busca de trabalho e estudo.

A origem da problemática que envolve a expansão do agronegócio nesse território está relacionada principalmente à venda da terra pelos próprios quilombolas, antes da regularização fundiária (ainda não realizada pelo INCRA). A aquisição das terras deu-se por agentes privados oriundos do próprio Tocantins e de outros estados, sem a intervenção direta de políticas públicas, especialmente a partir de 2000. 
Entre os sujeitos foram registrados relatos de transações a preços irrisórios e trocas por bens de menor valor, mas também pagamentos não efetuados pelos compradores, cercamentos e documentação de áreas superiores àquelas negociadas, o que pode ensejar a prática de grilagem. Inúmeros são os motivos para a venda da terra, como o tamanho das áreas resultantes após a divisão entre herdeiros, a falta de recursos para a estruturação e a produção na terra, a obtenção da aposentadoria e as dificuldades de acesso à água. Tal situação faz com que, hoje, sejam poucas as famílias quilombolas que ainda detêm a posse de terras, principalmente após o processo de territorialização do agronegócio na região ter sido acelerado.

Anteriormente a esse cenário, os sistemas produtivos tradicionais existiam em consonância com o uso coletivo do território, por parte dos quilombolas. Entre os pilares de sustentação das famílias estavam a criação extensiva de gado e as chamadas roças de toco. "Nem gado, nem terra, não tinha valor nesse tempo(.)" (Suj.12), explica um sujeito. O gado era criado solto, assim como outras criações, recebendo somente a marcação de cada proprietário, alimentando-se com capim nativo e frutos do Cerrado. As roças de toco, para o plantio de arroz, feijão, milho, abóbora, amendoim e mandioca, eram formadas por cada família, em um sistema de rodízio que garantia a agrobiodiversidade e permitia a regeneração florestal nas pequenas clareiras abertas na vegetação (Fotografias 1A e 1B). Além dessas práticas, as estratégias alimentares incluíam ainda a caça e a pesca abundantes no território, enquanto o abastecimento de água se dava por meio de inúmeras nascentes e cacimbas espalhadas nos arreadores das moradias, no povoado. 
Fotografias 1A e 1B - Roça de toco usada na comunidade quilombola, em 2001 (A); Lavoura de soja tendo ao fundo o morro que deu origem à denominação da comunidade, em 2018.

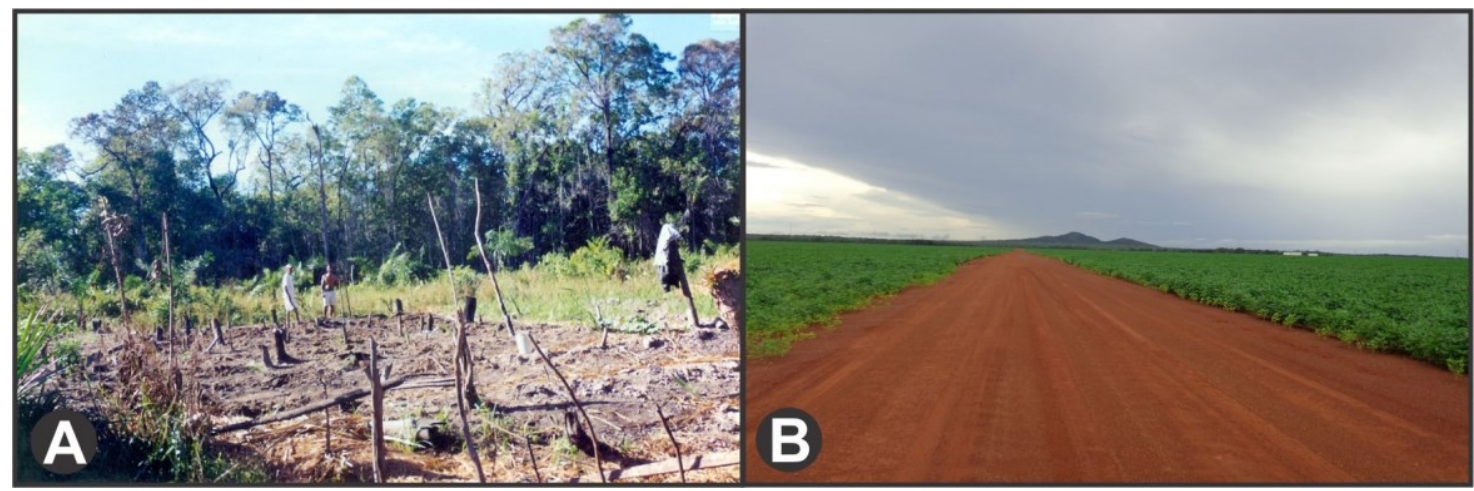

Fonte: acervo pessoal de A. R. N. (membro da comunidade quilombola) (A); primeiro autor (B).

Tal arranjo, segundo os sujeitos, favorecia o compartilhamento dos alimentos entre as famílias, o trabalho e a vida em comunidade, em uma rotina diária que consistia em se trabalhar no território ao longo do dia, aproveitando seus bens comuns, retornando ao povoado para o descanso à noite. Por um lado, tratava-se de um metabolismo ou relação orgânica capaz de configurar certa condição de equilíbrio e permitir o autossustento, empregando o termo resgatado de Marx por Suertegaray (2017). Por outro lado, pela ótica do conceito de Diegues (2005), também usado por MazzettoSilva (2009), tal relação entre a comunidade e a natureza expressava um modelo baseado na sociobiodiversidade, com benefícios mútuos e relativa autonomia.

A partir das mudanças verificadas no território houve a quebra desse modelo na comunidade quilombola. Entre as primeiras consequências do parcelamento/venda da terra e da presença das lavouras comerciais, destacase a inviabilidade para a manutenção do rebanho e para o plantio de roças, seja diretamente pela falta de terra, pela nova necessidade de cercar os animais e, por conseguinte, de cultivar pastagens, entre outras coisas. Essa nova realidade acabou por reduzir a atividade da pecuária e da agricultura entre os quilombolas, sendo que hoje são poucos aqueles que ainda detêm algumas cabeças de gado e plantam suas roças. Segundo um dos sujeitos, "já 
[está] com três anos que só o povo rico que planta soja. Aí nós largamos de plantar roça. Todo mundo daqui, né?!(.)" (Suj.4).

A supressão da vegetação natural para a introdução das lavouras comerciais tem sido outra severa implicação do agronegócio, uma vez que traz consequências ambientais mais amplas em relação à água, ao clima e à fauna, por exemplo. "[...] Já tá tudo vendido, tudo derrubado, esquisito(.)” (Suj.2), comenta um dos sujeitos. Os entrevistados mostram consciência sobre muitas dessas relações, estabelecendo nexos causais entre o desmatamento e vários tipos de problemas ambientais a que estão hoje submetidos. Até mesmo o aspecto da livre movimentação das pessoas pelo território é lembrado, uma vez que muitos utilizavam caminhos alternativos e trilhas por entre as matas para acessar diferentes lugares, aproveitando a sombra, alternativa cada vez menos viável.

Entre os aspectos climáticos, os sujeitos indicam o aumento da sensação de calor e a significativa redução de tipos de tempo atmosférico com temperaturas mais amenas que eram comuns em meados do ano, conforme relatos. Essas condições podem estar ao menos parcialmente relacionadas às mudanças locais e microclimáticas promovidas pela retirada da vegetação natural ao longo do território quilombola e nos arredores. Soma-se a isso a tendência, observada pelos pesquisadores nos trabalhos de campo, de substituição gradual dos materiais e técnicas empregados pelos quilombolas, como o adobe e a taipa, que foram trocados por construções convencionais de alvenaria, que contribuem para o desconforto térmico.

Em relação às chuvas, os sujeitos também revelam mudanças percebidas em seu regime/regularidade, especialmente por meio de relatos a respeito das frequentes enchentes que atingiam a área no passado, mas que atualmente não têm mais ocorrido. Este, aliás, também tem sido um fator limitante para o plantio de roças na comunidade. Nas palavras de um sujeito, "[...] tinha os meses que já eram controlados, você fazia os planos: vamos começar a plantar em tal mês porque é o tempo das chuvas. Aí vai chover de 
tal mês até tal mês [...]. Hoje você não faz isso aí, você termina é perdendo [...]" (Suj.3). Em termos gerais, a situação delineada muito se assemelha àquela demonstrada por Barros (2012), no caso da Comunidade Quilombolas dos Kalunga, em Goiás.

Ainda com relação à dinâmica das águas, a escassez hídrica é outro ponto muito presente no discurso dos sujeitos. Os cursos d'água vêm perdendo sua perenidade ao longo dos últimos anos, sendo que muitos passaram a secar completamente durante a estiagem. $\mathrm{O}$ antigo abastecimento domiciliar, por meio das nascentes e cacimbas com água de boa qualidade, foi abandonado, por conta do esgotamento desses mananciais. Em substituição, passou a ser utilizada, por intermédio de um poço semi-artesiano perfurado no povoado, a água encanada até as moradias, embora seja prevalente a desaprovação dos moradores quanto à qualidade da água (salobra) e ao excesso de cloro adicionado no tratamento (Fotografias 2A e 2B). Assim, os moradores continuam buscando por outras fontes de água para o consumo diário (em cisternas, por exemplo), empregando a água encanada somente para limpeza doméstica, em sua maioria. "A gente tá bebendo é de umas casas vizinhas aqui, porque a água [encanada] é muito salgada” (Suj.8), explica um sujeito.

Fotografias 2A e 2B - Leito (seco) do córrego Estiva, em agosto/2017 (A); Poço semi-artesiano e sistema de tratamento da água com cloro, em dezembro/2017.

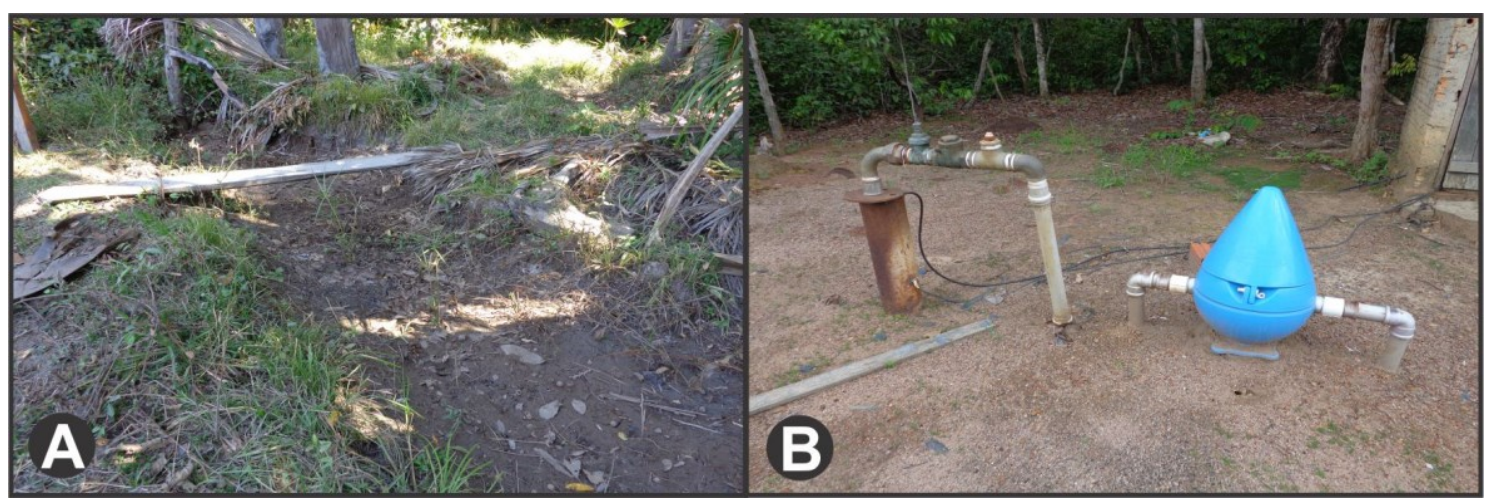

Fonte: primeiro autor. 
Entre os cursos d'água de menor porte, que cruzam o território quilombola, estão os córregos Borá, Estiva e Atoleiro (conforme anteriormente evidenciado nos mapas 2 e 3), porém há receio quanto ao consumo da água em decorrência da possível contaminação por agrotóxicos carreados das lavouras pelo escoamento superficial, denunciada pelo aspecto da água após os episódios de chuva. A pulverização desses produtos nas lavouras, por via terrestre ou por aeronave, é um fato que preocupa os sujeitos, que relatam mau cheiro e morte de plantas, como hortaliças, pequenas roças de milho e capim no entorno das grandes lavouras. A deriva atmosférica de agrotóxicos nessa área pode ser potencializada pela incidência de ventos de leste/sudeste, pela atuação regular da Massa Tropical Atlântica sobre o Tocantins, já que a comunidade está a sotavento das áreas de plantio de soja no município (SOUZA, 2016b).

Diante desse cenário, a redução da fauna torna-se consequência muito provável, a começar pela redução de habitats e fragmentação da vegetação nativa. Ainda que possa haver interferência de caça predatória e da ocorrência de queimadas no quantitativo das populações, os sujeitos apontam queda acentuada dos animais silvestres avistados no território quilombola ao longo dos últimos anos, como veados e antas. Relatam ainda a incursão frequente de caçadores externos à comunidade e a presença de armadilhas de caça, chamadas de "trabucos". Concomitante, a comunidade tem vivido assustada e vem, ao longo dos anos, mudando seus hábitos em função do aumento das ocorrências de felinos (onças) na área, descrevendo inúmeros casos em que vacas, cães, porcos e até equinos têm servido de alimento a esses animais, o que pode estar relacionado à falta de outras presas na natureza.

A ictiofauna também tem passado por redução sistemática nos cursos d'água que drenam o território quilombola, sendo que os sujeitos relatam o desaparecimento de algumas espécies de peixes, como surubim, fidalgo, traíra, jaú, piabanha e iuiu. Entre as possíveis razões, podem ser listadas a pesca predatória, a contaminação das águas por agrotóxicos, a construção de 
hidrelétricas na bacia do rio Tocantins e a escassez hídrica especialmente nos pequenos cursos d'água. Logo, os quilombolas percebem a gradual redução do hábito da pesca na comunidade, prática agora ocasional e realizada em locais mais distantes.

O uso medicinal de plantas e de frutos silvestres para a alimentação também integra o rol de saberes e tradições da comunidade quilombola, sendo prática comum entre os sujeitos entrevistados e suas famílias. No entanto, há também relatos de diminuição da ocorrência de determinadas variedades no âmbito do território, a exemplo do baru, da sucupira, da mangaba, do murici e do puçá. Conforme afirmam os sujeitos, as plantas medicinais encontradas em áreas de vegetação ciliar ainda são mais fáceis de se obter na natureza, em função da manutenção obrigatória das áreas de proteção permanente (APP) fluviais. Porém, aquelas típicas de ambientes e terrenos usados para o plantio de lavouras, vêm sendo suprimidas juntamente com o restante da vegetação.

Conforme um dos sujeitos, "[...] estamos vivendo aqui é do supermercado"(Suj.2). Essas palavras, reproduzidas de uma das entrevistas, sintetiza todo o conjunto de mudanças em relação aos modos de vida, à rotina, ao trabalho e às fontes de alimento e água, entre os quilombolas de Morro de São João, instituído a partir da presença do agronegócio em seu território. Rompe-se o metabolismo com a natureza, exigindo adaptações progressivas quanto aos diferentes hábitos e tradições, assim como aquelas verificadas em outras comunidades tradicionais, como os casos retratados por Guyot et al (2006), Chaveiro (2010) e Barbosa e Camenietzki (2011). O Quadro 1 a seguir busca apresentar as principais mudanças verificadas na comunidade e abordadas no artigo, ressaltando-se o vínculo entre as diferentes dimensões. 
Quadro 1 - Síntese das condições anteriores e posteriores à presença do agronegócio junto ao território da Comunidade Quilombola Morro de São João

\begin{tabular}{|c|c|c|}
\hline Dimensão & $\begin{array}{c}\text { Condições anteriores à presença do } \\
\text { agronegócio junto ao território } \\
\text { quilombola }\end{array}$ & $\begin{array}{c}\text { Condições posteriores à presença do } \\
\text { agronegócio junto ao território } \\
\text { quilombola }\end{array}$ \\
\hline 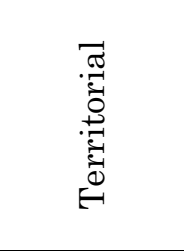 & $\begin{array}{l}\text { Uso livre/coletivo do território; } \\
\text { Ausência de cercas e delimitações } \\
\text { internas; } \\
\text { Ausência de documentação } \\
\text { fundiária. }\end{array}$ & $\begin{array}{l}\text { Desintegração do território, uso } \\
\text { limitado/privado da terra; } \\
\text { Presença de cercas nas divisas } \\
\text { internas; } \\
\text { Organização de documentação } \\
\text { fundiária. }\end{array}$ \\
\hline 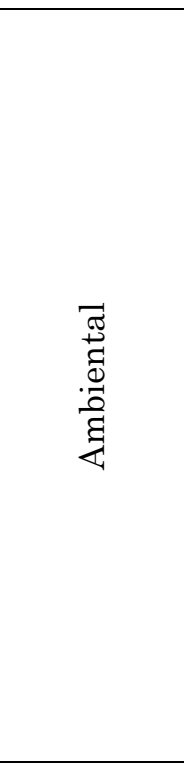 & $\begin{array}{l}\text { Maiores domínios de vegetação } \\
\text { natural (matas, cerrado); } \\
\text { Capim nativo como pastagem; } \\
\text { Farta disponibilidade hídrica } \\
\text { (nascentes e rios); } \\
\text { Abundância de fauna silvestre e } \\
\text { ictiofauna; } \\
\text { Baixo uso de agrotóxicos } \\
\text { (quilombolas); } \\
\text { Raros avistamentos e ocorrências } \\
\text { envolvendo felinos; } \\
\text { Temperatura do ar mais amena e } \\
\text { frequente sensação de frio; } \\
\text { Maior abundância e regularidade } \\
\text { das chuvas; } \\
\text { Facilidade para encontrar variedade } \\
\text { de plantas medicinais na vegetação } \\
\text { natural. }\end{array}$ & $\begin{array}{l}\text { Menores domínios de vegetação } \\
\text { natural (matas, cerrado); } \\
\text { Pastos cultivados (espécies exóticas); } \\
\text { Escassez hídrica (nascentes e rios); } \\
\text { Redução da fauna silvestre e da } \\
\text { ictiofauna; } \\
\text { Amplo uso de agrotóxicos } \\
\text { (sojicultores); } \\
\text { Frequentes avistamentos e } \\
\text { ocorrências envolvendo felinos; } \\
\text { Temperatura do ar mais alta e } \\
\text { frequente sensação de calor; } \\
\text { Menor abundância e irregularidade } \\
\text { das chuvas; } \\
\text { Dificuldade para encontrar } \\
\text { determinadas plantas medicinais na } \\
\text { vegetação natural. }\end{array}$ \\
\hline $\begin{array}{l}\frac{\pi}{0} \\
\frac{1}{5} \\
0 \\
0 \\
0 \\
8 \\
0 \\
\Sigma\end{array}$ & $\begin{array}{l}\text { Hábito do plantio de roças de toco; } \\
\text { Agricultura de autossustentação e } \\
\text { venda de excedente agrícola; } \\
\text { Abundância de criações (gado, suínos } \\
\text { e aves) soltas ; } \\
\text { Abastecimento domiciliar de água } \\
\text { via cacimbas; } \\
\text { Amplo uso de remédios naturais; } \\
\text { Hábito de incursões nas matas para } \\
\text { caçar; } \\
\text { Frequentes pescarias em locais } \\
\text { próximos; } \\
\text { Uso de materiais e técnicas } \\
\text { construtivas tradicionais (barro, } \\
\text { madeira, palmáceas). }\end{array}$ & $\begin{array}{l}\text { Abandono do plantio de roças de toco; } \\
\text { Aquisição de alimentos no varejo } \\
\text { local; } \\
\text { Poucas criações (gado, suínos e aves) } \\
\text { cercadas/confinadas; } \\
\text { Abastecimento domiciliar de água via } \\
\text { poço semi-artesiano e encanamento } \\
\text { (água clorada); } \\
\text { Limitado uso de remédios naturais; } \\
\text { Uso de armadilhas para caçar } \\
\text { ("trabucos"); } \\
\text { Pescarias ocasionais e em locais mais } \\
\text { distantes; } \\
\text { Substituição gradual por materiais e } \\
\text { técnicas construtivas convencionais. }\end{array}$ \\
\hline
\end{tabular}

Organização dos autores, 2018. Fonte: trabalho de campo, 2018.

Tomando como referência as ideias de Zhouri e Laschefski (2010), observa-se que as implicações do agronegócio na área de estudo instituem conflitos ambientais de cunho territorial, espacial e distributivo. Territorial, 
em decorrência da sobreposição de interesses, ainda que por motivações muito distintas, sobre a mesma área. Espacial, em função da nítida propagação dos prejuízos causados, seja pela livre circulação da água, do ar e da fauna. Distributivo, pelas dificuldades crescentes de acesso aos bens comuns da natureza, a exemplo da água potável, ainda que não haja, por enquanto, projetos de agricultura irrigada na área, o que poderia agravar potencialmente os problemas dessa comunidade.

Apesar da exposição teórica do conflito emprestada por Zhouri e Laschefski (2010), a relação de subordinação e as divergências entre quilombolas e fazendeiros encontram-se frequentemente veladas, por intermédio de estratégias de aproximação pela via do trabalho (contratação de trabalhadores temporários na comunidade), doações de alimentos nas moradias e patrocínio a festejos religiosos, por parte do segundo grupo. Há certa passividade, além de uma declarada humildade entre os comunitários, o que comparece com frequência nas entrevistas.

É notório que o desequilíbrio financeiro e de acesso aos mecanismos jurídicos de proteção à propriedade, entre os dois grupos, acaba por favorecer tal subordinação. Porém, ainda que haja insatisfação quanto às mudanças vividas e preocupação quanto ao futuro da comunidade, os sujeitos mostramse enraizados em seu território: "[...] enquanto eu der conta de andar, fazer minha comida, eu não saio daqui não. Acho muito bom(.) (Suj.9), palavras que expressam o tom de resistência da Comunidade Quilombola Morro de São João.

As reflexões apresentadas clarificam o seguinte: a expansão do agronegócio, no Tocantins, de maneira geral, e em torno da Comunidade Quilombola Morro de São João, em particular, compreende um estatuto geopolítico do qual se situa, na escala mundial, o que se denomina financeirização da produção de alimentos; na escala nacional, o pacto de poder entre o Estado e o setor ruralista; e nas escalas regional e local, o 
empreendimento de uma economia cujo desdobramento é a injustiça ambiental e a fragmentação das identidades originárias.

Contudo, conforme se percebeu em campo - e mediante as rodas de prosa e entrevistas -, embora com conflitos internos, há uma organização de um arco de poder resistente no qual se encontra especialmente a presença de lideranças de movimentos sociais e de setores acadêmicos da universidade. Observa-se, ainda, que a organização da resistência inclui, de um lado, o embate ideológico, no qual latifundiários vinculados ao agronegócio tentam cercear a organização com oferta de presentes às lideranças e com pressão; de outro lado, o discurso de que o pertencimento dos sujeitos da comunidade, sua filiação cultural e seus lastros de sociabilidade deverão ser a premissa de vida que sustenta a luta.

A interpretação territorial de comunidades quilombolas tem sido, na geografia brasileira contemporânea, uma forma de, a partir especialmente das contribuições de geógrafos como Haesbaert (1997) e Porto-Gonçalves (2004), alargar a compreensão do poder e seus vínculos com os sujeitos e seus modos de vida. Observa-se, também, em autores como Almeida (2009) e Mendonça (2004), dentre outros, uma premissa: todo processo de ação territorial, ao envolver sujeitos concretos, incita tomadas de posição, resistências, articulações políticas e solidárias no interior dos segmentos atingidos e pressionados. Em muitos casos, como se vê na Comunidade Quilombola Morro de São João, a organização parte de sua própria associação comunitária (Fotografias 3A e 3B) - da articulação junto ao campo político e de discernimento dos problemas à afirmação cultural devotando que as lutas devem falar a voz da vida. 
Fotografias 3A e 3B - Placa com logomarca na sede da Associação Quilombola Morro de São João, em agosto/2017 (A); Assembleia da Associação Quilombola Morro de São João, em janeiro/2018 (B).

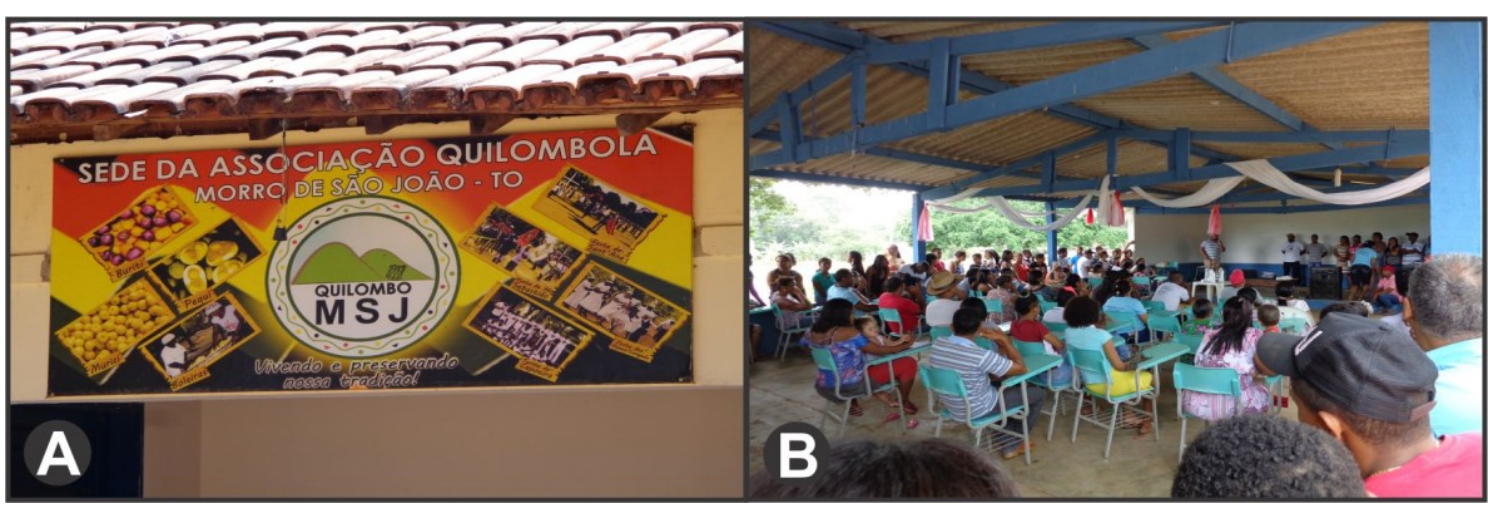

Fonte: primeiro autor

\section{Considerações Finais}

Ao final deste artigo, percebe-se que as inúmeras tensões originadas pelo avanço da fronteira agrícola sobre a comunidade quilombola em foco apresentam-se em diferentes dimensões: as questões territoriais são as primeiras a se manifestar, envolvendo a lentidão da regularização fundiária e a transferência gradual de terras para o setor do agronegócio; a partir da implantação de uma nova lógica produtiva por meio das grandes lavouras comerciais, sobressaem-se os variados problemas ambientais que envolvem especialmente a água, o ar e a biota; por último, o próprio modo de vida da comunidade, incluindo seus saberes e fazeres, acaba por tornar-se comprometido. Essa articulação demonstra a própria complexidade da vida material e simbólica, amplificando o papel da organização comunitária, de sua resistência e luta pela terra, pela natureza e pela cultura.

Porém, tratar os conflitos entre o agronegócio e as comunidades tradicionais no Brasil de hoje implica considerar não somente a complexidade de casos particulares, como o que foi aqui demonstrado, mas sobretudo a conjuntura desfavorável à garantia dos direitos até então conquistados por esses povos. No momento em que o setor do agronegócio se mostra organizado em defesa da propriedade privada da terra e da livre exploração da natureza 
pelo capital, em conjunto com outras alas conservadoras da sociedade, colocase em xeque a possibilidade de reprodução de todo o conjunto da sociobiodiversidade no país.

No plano acadêmico, de modo especial no campo da Geografia, ressaltam-se os desafios para a abordagem solidária do tema, ampliando as perspectivas para a elucidação dos fatos e fenômenos em tela, juntamente com a possibilidade de aprendizado mútuo entre as diferentes disciplinas e correntes. Nesse quesito, os problemas territoriais e ambientais se entrelaçam, tornando-se concretamente evidentes no cotidiano, no vivido.

Do ponto de vista das comunidades tradicionais, não se trata de idealizar a vida campesina, isentando os sujeitos de suas responsabilidades, mas reconhecendo seu protagonismo, sua necessária autocrítica e seu posicionamento frente às circunstâncias complexas que envolvem seu passado, presente e futuro. O sentido da empiria, notabilizado pelo trabalho de campo, é pródigo em revelar a riqueza de conexões e as inúmeras contradições individuais e coletivas que acabam por desenhar a situação de um povo que busca garantir o seu próprio espaço e, em última instância, a sua própria existência.

Por fim, diante dos muitos temas que emergem da relação entre território e ambiente no enquadramento proposto, destacam-se algumas iniciativas em termos de pesquisas mais detalhadas de campo, de forma interconectada e cooperativa, tais como: aprofundar o conhecimento sobre as implicações do agronegócio em comunidades tradicionais quanto aos aspectos do clima (formação de microclimas e balanço de radiação), da água (contaminação por agrotóxicos, escassez e manejo), da fauna e da flora (comportamento frente às mudanças nos habitats e extinção de populações), da estrutura social e econômica (detalhamento da situação fundiária, condições de trabalho e renda, acesso às políticas públicas de infraestrutura, saúde, educação e moradia), e da cultura (alimentação, cotidiano, tradições e 
religiosidade). Refere-se, nesse caso, a uma ampla agenda, ao mesmo tempo política e científica, com a qual nos defrontamos.

\section{Agradecimentos}

À CAPES, pela concessão de bolsa de estudos no âmbito do Edital PGPSE n.42/2014, Projeto Desenvolvimento territorial e sociobiodiversidade: perspectivas para o mundo do Cerrado (Parceria UFG/UFU/UFT).

\section{Referências}

ACSELRAD, H.; MELLO, C. C. A.; BEZERRA, G. N. O que é justiça ambiental. Rio de Janeiro: Garamond, 2009.

ALMEIDA, A. W. B. de. Direitos territoriais e étnicos: as estratégias dos agronegócios na Amazônia. In: ZHOURI, A.; LASCHEFSKI, K. (org.) Desenvolvimento e conflitos ambientais. Belo Horizonte: Editora UFMG, 2010, p.382-387.

ALMEIDA, M. G. de. Diásporas: viver entre-territórios e entre-culturas? In: SAQUET, M. A.; SPOSITO, E. S. (Org.). Territórios e territorialidades: teorias, processos e conflitos. São Paulo: Expressão Popular, 2009. p.175-195.

BARBOSA, R. S.; CAMENIETZKI, C. P. A. Comunidades tradicionais e conflitos ambientais territoriais no norte de Minas Gerais. In: COLÓQUIO INTERNACIONAL POVOS E COMUNIDADES TRADICIONAIS, 2, 2011, Montes Claros. Anais... Montes Claros: UNIMONTES, 2011, 18p. [impresso].

BARROS, J. R. A percepção ambiental dos quilombolas Kalunga do Engenho e do Vão de Almas acerca do clima e do uso da água. Ateliê Geográfico, Goiânia, v.6, n.4, p.216-236, 2012. Acesso em: 26 out. 2017. http://dx.doi.org/10.5216/ag.v6i4.21980

BAUER, M. W.; AARTS, B. A construção do corpus: um princípio para a coleta de dados qualitativos. In: BAUER, M. W.; GASKELL, G. (Org.). Pesquisa qualitativa com texto, imagem e som: um manual prático. 11 ed. Petrópolis: Vozes, 2013, p.39-63.

CARVALHO, G. S. Regularização fundiária dos territórios quilombolas: direito à propriedade, titulação e permanência na terra da população negra do Estado do Tocantins. Escritas, Araguaína, v.3, p.103-119, 2011. Disponível em: https://sistemas.uft.edu.br/periodicos/index.php/escritas/article/view/1294 Acesso em: 29 nov. 2017.

CHAVEIRO, E. F. Cerrado e território: conflitos socioespaciais na apropriação da biodiversidade - os povos indígenas Karajás, Aruanã-GO. Ateliê Geográfico, Goiânia, v.4, n.1, edição especial, p.64-83, 2010. Acesso em: 20 out. 2016. http://dx.doi.org/10.5216/ag.v4i1.16683

CLETO, E. A. T. Resiliência e reconhecimento em neocomunidade: o caso da Comunidade Quilombola Morro de São João - TO. 2015. 211f. Dissertação (Mestrado em Desenvolvimento Regional) Universidade Federal do Tocantins, Campus de Palmas, Palmas, 2015. Disponível em: http://hdl.handle.net/11612/188 Acesso em: 24 nov. 2017.

COPE, M. Coding transcripts and diaries. In: CLIFFORD, N.; FRENCH, S.; VALENTINE, G. (Ed.). Key methods in Geography. London: Sage, 2010, p.440-452.

DIEGUES, A. C. (org.) Biodiversidade e comunidades tradicionais no Brasil. São Paulo: NUPAUB-USP/PROBIO-MMA/CNPq, 2000.

DIEGUES, A. C. Sociobiodiversidade. In: FERRARO JÚNIOR, L. A. (Org.) Encontros e caminhos: formação de educadoras(es) ambientais e coletivos educadores. Brasília: MMA, 
2005, p.303-312.

FIABANI, A. Os novos quilombos: luta pela terra e afirmação étnica no Brasil (1988-2008). 2008. 275f. Tese (Doutorado em História) Universidade do Vale do Rio dos Sinos, São Leopoldo, 2008. $\quad$ Disponível em: http://www.repositorio.jesuita.org.br/handle/UNISINOS/2177 Acesso em: 15 jan. 2018.

GASKELL, G. Entrevistas individuais e grupais. In: BAUER, M. W.; GASKELL, G. (org.) Pesquisa qualitativa com texto, imagem e som: um manual prático. 11 ed. Petrópolis: Vozes, 2013, p.64-89.

GUYOT, M.; DICKSON, C.; PACI, C.; FURGAL, C.; CHAN, H. M. Local observations of climate change and impacts on traditional food security in two northern aboriginal communities. International Journal of Circumpolar Health, [s.l.], v. 65, n. 5, p.403-415, 2006. Acesso em: 26 out. 2017. https://doi.org/10.3402/ijch.v65i5.18135

HAESBAERT, R. Des-territorialização e identidade: a rede "gaúcha" no nordeste. Rio de Janeiro: EDUFF, 1997.

HOEFLE, S. W. A fronteira agrícola na Amazônia do século XXI: identidade regional, sistema agrícola, ética ambiental e modo de vida rural. Revista Brasileira de Geografia, Rio de Janeiro, v.62, n.1, p.13-50, 2017. Acesso em: 10 dez. 2017. https://doi.org/10.21579/issn.2526$\underline{0375 \quad 2017 \text { n1 p13-50 }}$

JAKKU, E.; THORBURN, P. J.; MARSHALL, N. A.; DOWD, A. M.; HOWDEN, S. M.; MENDHAM, E.; MOON, K.; BRANDON, C. Learning the hard way: a case study of an attempt at agricultural transformation in response to climate change. Climatic Change, [s.1.], v.137, p.557-574, 2016. Acesso em: 6 set. 2017. http://dx.doi.org/10.1007/s10584-0161698-x

LIMA, D. A. A expansão da fronteira agrícola moderna nos cerrados do Centro-Norte e o avanço dos monocultivos da soja no Tocantins. In: ALVES, V. E. L. (Org.) Modernização e regionalização nos Cerrados do Centro-Norte do Brasil. Rio de Janeiro: Consequência, 2015, p.325-351.

LONGHURST, R. Semi-structured interviews and focus groups. In: CLIFFORD, N.; FRENCH, S.; VALENTINE, G. (Ed.). Key methods in Geography. London: Sage, 2010, p.103-115.

MAZZETTO-SILVA, C. E. Ordenamento territorial no Cerrado brasileiro: da fronteira monocultora a modelos baseados na sociobiodiversidade. Desenvolvimento e Meio Ambiente, Curitiba, v.19, p.89-109, 2009. Acesso em: 10 out. 2016. https://doi.org/10.5380/dma.v19i0.16407

McCARL, B. A. Analysis of climate change implications for agriculture and forestry: na interdisciplinary effort. Climatic Change, [s.l.], v.100, p.119-124, 2010. Acesso em: 6 set. 2017. http://dx.doi.org/10.1007/s10584-010-9833-6

MEINKE, H.; HOWDEN, S. M.; STRUIK, P. C.; NELSON, R.; RODRIGUEZ, D.; CHAPMAN, S. C. Adaptation science for agriculture and natural resource management: urgency and theoretical basis. Current Opinion in Environmental Sustainability, [s.1.], v.1, p.69-76, 2009. Acesso em: 08 ago. 2017. https://doi.org/10.1016/j.cosust.2009.07.007

MENDONÇA, M. R. A urdidura do trabalho e do capital no Cerrado do Sudeste Goiano. 2004. 457f. Tese (Doutorado em Geografia) Faculdade de Ciências e Tecnologia, Universidade Estadual Paulista, Presidente Prudente, 2004.

MONEGO, E. T.; PEIXOTO, M. R. G.; CORDEIRO, M. M.; COSTA, R. M. (In)segurança alimentar de comunidades quilombolas do Tocantins. Segurança Alimentar e Nutricional, Campinas, v.17, n.1, p. 37-47, 2010. Acesso em: 29 nov. 2017. https://doi.org/10.20396/san.v17i1.8634798

OSÓRIO, R. M. L.; AZEVEDO, D. B. Percepções dos especialistas frente às mudanças climáticas: integração lavoura-pecuária-floresta como alternativa sustentável à produção de alimentos, fibras e energia no agronegócio. Revista em Agronegócio e Meio Ambiente, Maringá, v.7, n.2, p. 257-278, 2014. Disponível em: http://periodicos.unicesumar.edu.br/index.php/rama/article/view/2814/2326 Acesso em: 18 nov. 2017. 
PIRES, A. P. Amostragem e pesquisa qualitativa: ensaio teórico e metodológico. In: POUPART, J. et al. (Org.) A pesquisa qualitativa: enfoques epistemológicos e metodológicos. Petrópolis: Vozes, 2008, p. 154-211.

PORTO-GONÇALVES, C. W. Geografando nos varadouros do mundo, Brasília: IBAMA, 2004.

POUPART, J. A entrevista do tipo qualitativo: considerações epistemológicas, teóricas e metodológicas. In: POUPART, J. et al. (Org.) A pesquisa qualitativa: enfoques epistemológicos e metodológicos. Petrópolis: Vozes, 2008, p. 215-253.

RICHARDS, P. What drives indirect land use change? How Brazil's agriculture sector influences frontier deforestation. Annals of the Association of American Geographers, Washington, v.105, n.5, p. 1026-1040, 2015. Acesso em: 22 out. 2017. https://doi.org/10.1080/00045608.2015.1060924

SOUZA, L. B. Implicações climáticas de um modelo neodesenvolvimentista: impactos, riscos e injustiças no Estado do Tocantins. Revista Brasileira de Climatologia, Curitiba, v.19, p.129-145, 2016a. Acesso em: 18 jan. 2017. http://dx.doi.org/10.5380/abclima.v19i0.48877

Ritmo climático e tipos de tempo no Estado do Tocantins, Brasil. In: SIMPÓSIO BRASILEIRO DE CLIMATOLOGIA GEOGRÁFICA, 12, 2016, Goiânia. Anais... Goiânia: UFG/ABCLIMA, 2016b, p.2266-2277. Disponível em: www.abclima.ggf.br/sbcg2016/anais/arquivos/eixo_5/trabalho\%20(10).pdf Acesso em: 23 fev. 2018.

SUERTEGARAY, D. (Re)ligar a Geografia: natureza e sociedade. Porto Alegre: Compasso Lugar-Cultura, 2017.

UNIVERSIDADE FEDERAL DE GOIÁS (UFG). Instituto de Estudos Socioambientais. Laboratório de Processamento de Imagens e Geoprocessamento. Inteligência Territorial. 2017. Disponível em: https://www.lapig.iesa.ufg.br/lapig/ Acesso em: 19 ago. 2017.

ZHOURI, A.; LASCHEFSKI, K. Desenvolvimento e conflitos ambientais: um novo campo de investigação. In: ZHOURI, A.; LASCHEFSKI, K. (Org.) Desenvolvimento e conflitos ambientais. Belo Horizonte: Editora UFMG, 2010, p.11-31. 